\title{
Beyond Books: The Extended Academic Benefits of Library Use for First-Year College Students
}

\section{Krista M. Soria, Jan Fransen, and Shane Nackerud}

The purpose of this paper was to investigate whether there are relationships between first-year college students' use of academic libraries and four academic outcomes: academic engagement, engagement in scholarly activities, academic skills development, and grade point average. The results of regression analyses suggest students' use of books (collection loans, e-books, and interlibrary loans) and web-based services (database, journal, and library website logins) had the most positive and significant relationships with academic outcomes. Students' use of reference services was positively associated with their academic engagement and academic skills, while enrollment in library courses was positively associated with grade point averages.

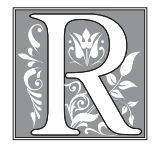

esearchers are beginning to heed calls to more formally investigate the abeyant benefits of college and university academic libraries for one of their largest groups of constituents - undergraduate college students. For instance, scholars have provided evidence for the positive associations between college students' use of academic libraries, fall semester grade point averages, and retention from fall to spring semester. ${ }^{1}$ These benefits also extend to students' retention from their first year to their second year of enrollment and to their final first-year cumulative grade point average. ${ }^{2}$ Similar studies have revealed positive associations between the number of books students borrowed and their grade point average, ${ }^{3}$ as well as significant relationships between the number of resources held at libraries and students' development of critical thinking skills. ${ }^{4}$ In an earlier study, Wells also found statistically significant and positive correlations between students' use of academic library resources (such as borrowed books, journal articles, items in the reserve collection) and their academic achievement. ${ }^{5}$ The effects of these research studies have helped move librarians from simply asserting that their libraries positively promote students' learning to truly understanding the ways in which students' use of academic libraries is associated with their learning and academic success. ${ }^{6}$

Despite the growing body of literature in this area, there is still too little evidence regarding the multifaceted ways in which students' use of academic libraries is as-

Krista M. Soria is an Analyst in the Office of Institutional Research, Jan Fransen is Service Lead: Researcher and Discovery Systems, and Shane Nackerud is Technology Lead, Library Initiatives, all at the University of Minnesota; e-mail: ksoria@umn.edu, fransen@umn.edu, snackeru@umn.edu. @2017 Krista M. Soria, Jan Fransen, and Shane Nackerud, Attribution-NonCommercial (http://creativecommons.org/ licenses/by-nc/3.0/) CC BY-NC. 
sociated with their academic outcomes. Furthermore, the extant body of literature has primarily focused on students' grade point averages as an academically related outcome or students' development of information literacy or critical thinking skills. Those outcomes not only make sense, given the nature of academic libraries and the roles they play on college campuses - they are also of high importance to higher education administrators, especially because outcomes like grade point averages are often strongly and positively associated with students' retention and degree completion. Yet, additional academic indicators - such as students' academic engagement, engagement in scholarly activities, and academic skills development-are also vitally important to students' success in higher education, although they remain unexplored in libraries' research and assessment studies to date.

Given the increased calls for accountability reverberating across the halls of higher education institutions - calls that have not gone unnoticed in academic and research library systems, as demonstrated by intensified assessment activities in libraries across the nation - we therefore designed the present study to examine whether students' use of academic libraries in their first year of college are associated with a wider array of academic outcomes. In particular, we investigated whether there are associations between first-year college students' use of academic libraries in five areas (books, web-based resources, reference resources, workstations, and instruction) and students' academic engagement, engagement in scholarly activities, academic skills development, and fall semester cumulative grade point average. Although previous studies have examined students' grade point averages as an outcome, we retained this dependent variable given its ongoing importance to administrators and the novel indicators of students' library use we explored in the study.

\section{Libraries and Students' Academic Outcomes}

Libraries are, by their functional and operational purposes, most commonly associated with the collegiate academic enterprise. Distinct from recreational centers or student centers, which may support students' wellness and social integration in higher education, most academic libraries feature the types of resources and materials (such as books and academic journals), study spaces, and group study rooms to support students' academic success and integration. As might be expected, there is some evidence to suggest that students who use library resources, interact with library staff, and spend more time using libraries tend to be more engaged with learning. ${ }^{7}$ This engaged learning, in turn, can positively promote students' academic achievement. For instance, researchers have discovered that students who borrow higher numbers of books are much more likely to obtain higher final exam grades in classes of varying academic subjects. ${ }^{8}$ Additionally, researchers have discovered that students' use of academic libraries is positively associated with students' ability to put together different facts and ideas, work on projects integrating ideas from various sources, apply course material to other aspects of their lives, and exert significant effort on academic material to meet faculty expectations. ${ }^{9}$

Like many other units within higher education institutions, libraries are increasingly under pressure to demonstrate the ways in which they support undergraduates' academic success, development, and retention. More recently, researchers have undertaken the important work of analyzing the associations between undergraduates' use of library resources as they may extend forward to students' degree attainment. ${ }^{10}$ While all of the aforementioned studies have revitalized the field of libraries assessment and established the value of academic libraries, there are questions that remain unanswered regarding the means through which students' use of libraries contributes to their success. It may be the case that students' use of academic library 
resources promotes their academic engagement and scholarly activities, which subsequently enhances their ability to be successful in classes and earn the credits necessary to complete their degrees. Unfortunately, at present, very little research exists that connects students' use of library resources (as derived from institutional data records and not students' self-reported library use) with some of those potentially moderating variables.

In this study, we sought to understand whether students' use of academic libraries is associated with their academic engagement, engagement in scholarly activities, academic skills development, and grade point average. We examined these associations among first-year college students to consider the effect of libraries use, as these effects may be more easily distinguished in students' first semester of enrollment from the constellation of collegiate experiences students encounter as they progress in their degree programs. In other words, in examining students' library use in their first semester, we eliminate the effects of later collegiate experiences that may also influence students' outcomes (example: the effect of being enrolled in courses strongly associated with students' academic interests may inspire students' academic engagement, thus confounding the outcomes).

\section{Conceptual Framework}

The conceptual framework for this study is built upon Astin's well-established InputEnvironment-Output model, which hypothesizes that the background characteristics of college students (inputs) and relevant aspects of the college experience (environment) influence outcomes. ${ }^{11}$ Adhering to this model, controls for inputs (such as sex, racial/ethnic identity, and precollege ratings of academic skills) and additional college experiences (such as campus climate, academic college of enrollment) were included as separate blocks in the models predicting students' academic outcomes to isolate their contributions from the focal independent variables - students' use of academic libraries in five broad areas.

\section{Methods \\ Sample}

In fall 2011, 5,368 nontransfer first-year students enrolled at the University of Minnesota. Of these students, we retained 1,068 for analyses, as these students completed the survey instrument described below. Within this first-year student cohort, the majority of students were female, white, and residents for tuition purposes. These students were primarily enrolled in one of seven colleges within the university, with the greatest percentage of students enrolled in a liberal arts college (39.64\%). The average age of students in the sample at the time of their enrollment was $18.14(\mathrm{SD}=.49)$.

\section{Instrument}

The Student Experience in the Research University (SERU) survey is administered annually within a consortium of large, public research universities that are members of the Association of American Universities. The SERU survey contains more than 600 items, and the purpose of the instrument is to gather data on students' satisfaction, academic engagement, use of time, collegiate experiences, and perceptions of campus climate, among other areas. In 2012, the SERU survey was administered to all eligible college students enrolled at the University of Minnesota, including the first-year students used in the present study. The survey was administered from March 2012 to July 2012, although the majority of respondents completed the survey in the first month of the administration. Of all of the first-year students, 19.90 percent $(n=1,068)$ responded to the survey items employed in the analyses. 


\section{Measures}

Block one: Precollege variables. We controlled for students' demographic characteristics, including sex, race/ethnicity, and international status. We also controlled for whether students had received Pell grants or were first-generation college students (in other words, neither parent had earned a bachelor degree). All of these demographic variables were dummy-coded, and frequencies are reported in table 1. Additionally, we included students' precollege academic characteristics: students' ACT composite scores and the number of AP credits that students had transferred into the university. When ACT scores were not present, we converted SAT composite scores to ACT scores based on ACT's recommended concordance tables.

Students' reports of their precollege academic skills were also included in this block. Rather than using change or growth scores in regression models, Pascarella, Wolniak, and Pierson suggested the inclusion of a statistical control for the pretest measures. ${ }^{12}$ When a statistical control for the pretest measure is included in the analysis, the impact of the independent variables on the posttest scores is functionally the same as the impact of the same independent variables on the growth or gains made from the pretest to the posttest. We therefore included measures of students' self-reported academic skills at the time they started college in four areas: analytical and critical thinking skills, ability to read and comprehend academic material, ability to be clear and effective when writing, and understanding of a specific field of study. Students rated their skills on a scale from 1 = very poor to $6=$ excellent.

Block two: Collegiate experiences. We controlled for the effects of three student experiences known to positively influence students' academic outcomes, including whether students lived on campus, participated in freshman seminars, and were members of the Access to Success (ATS) program, an advising community at this institution that provides personalized, holistic, and culturally competent advising that advances academic excellence, campus engagement, and professional development for students. ${ }^{13}$ We also controlled for students' academic college: there are seven large colleges for undergraduate students, and we combined two colleges - one admitting students in majors affiliated with science and engineering and the other admitting students in biological sciences. The colleges were all dummy-coded, with the largest admitting college-a liberal arts college primarily enrolling first-year students in an undeclared major - as the common referent. These variables were dummy-coded, and their frequencies are reported in table 1.

We included several survey items associated with students' experiences, including their perceptions of campus climate for diversity, sense of belonging, level of academic disengagement, classmate interactions, and the average amount of time they spent in academic activities per week. Prior scholars have suggested variables such as campus climate and sense of belonging are associated with students' academic engagement, so we used these variables in analyses. ${ }^{14}$ Furthermore, we hypothesized that students' academic disengagement (for instance, not reading for classes, skipping classes) would be negatively associated with their academic outcomes and that the frequency with which students worked with classmates on academic work would be positively associated with those outcomes. We also speculated that the amount of time students spent studying each week and the percentage of required reading they completed each academic year would be positively associated with their academic outcomes, so we controlled for these effects. Finally, we wanted to control for the effects of students' research skills on their academic outcomes to assess the significance of students' use of academic libraries as distinguished from their research abilities.

Students' perception of the campus climate for diversity was measured through eight items in which students were asked to rate their agreement that students of their 
race/ethnicity, socioeconomic status, gender, political beliefs, religious beliefs, immigrant background, sexual orientation, or physical/psychological/learning disability were respected on campus. Students' agreement was measured along a scale from $1=$ strongly disagree to $6=$ strongly agree, and these items had good reliability $(\alpha=.93)$.

To measure sense of belonging, students were asked to rate their satisfaction in two areas-overall social experience and overall academic experience-along a scale from 1 = very dissatisfied to $6=$ very satisfied. Students also rated their agreement that they felt like they belonged at the institution and that they would still choose to reenroll knowing what they knew about the institution now along a scale from $1=$ strongly disagree to 6 = strongly agree. The factor developed from these items had good reliability $(\alpha=.86)$.

To measure students' level of academic disengagement, students indicated the frequency with which they skipped classes, went to class without completing assigned reading, attended class unprepared, or turned in a course assignment late. Frequency was measured on a scale from $1=$ never to $6=$ very often, and the factor developed from these items had good reliability $(\alpha=.87)$. Additionally, students were asked to indicate the amount of required reading they completed each academic year on a scale from $1(0 \%$ to $10 \%)$ to $10(91 \%$ to $100 \%)$. Finally, students were asked to rate their current skills in three areas: library skills, research skills, and Internet skills. Students rated their skills on a scale from $1=$ very poor to $6=$ excellent, and the factor developed from these items had good reliability $(\alpha=88)$.

Block three: Library usage. We analyzed 10 collection points that featured students' use of online library services, use of collections, and interactions with library personnel (that is to say, face-to-face discussions with peer research consultants, participation in workshops or classes, and online chats with reference libraries). All library usage points were derived from students' first semester of enrollment. The academic libraries collected the 10 library usage variables automatically using scripts that authenticated and authorized users. We combined these 10 areas into five major groups: books (traditional loans, e-books, and interlibrary loans), web-based services (database logins, journal logins, and library website login), classes (introduction to libraries workshops, course-integrated instruction, and a libraries class), reference (consultation with a reference librarian or meeting with a peer research consultant), and computer workstation use. We summed students' use of the libraries in all of these areas and then recoded them to reflect whether students had ever used the libraries in those areas (1) or had never used the libraries in those areas (0) (see table 1).

Database logins, electronic book views, and electronic journal logins used a "clickthrough" script for licensed resources. The libraries captured user login information for the libraries website through the Drupal content management system. Collection loans - primarily book checkouts and renewals - were extracted from the university's Ex Libris Aleph ${ }^{15}$ catalog transaction records, and no distinctions were made between initial checkout and renewal. The libraries also extracted interlibrary loan transactions from the university's ILLiad service, an interlibrary loan management system provided and hosted by OCLC ${ }^{\circledR} .16$

The remaining four library usage points measured more of the interpersonal interactions happening within libraries. Reference transactions that occurred via live Internet chat were gathered from QuestionPoint ${ }^{\mathrm{TM}}$ and the data were parsed into a list of Internet IDs. ${ }^{17}$ Computer workstation use at the libraries required that users log in through a shared computer management software service called Cybrarian ${ }^{\mathrm{TM}} .{ }^{18}$ Login data included Internet ID and date of transaction and was extracted from the Cybrarian database. The libraries also hosted in-person workshops throughout the year in four on-campus libraries. Students could register for these free workshops through 
the libraries' Drupal registration module. ${ }^{19}$ With the peer research consultant service, trained undergraduates were hired to help students narrow down their research topic, choose keywords, evaluate articles and websites, and learn other key research skills. Consultations were by appointment, so the libraries harvested Internet IDs from appointment lists.

Dependent variables: Academic outcomes. Our primary dependent variables include students' academic engagement, academic skills development, and engagement in scholarship - three variables constructed from survey items - as well as the students' fall semester cumulative grade point average (GPA) derived from institutional records.

Students' academic engagement was measured through four items in which students indicated the frequency with which they brought up ideas or concepts from different courses during class discussions, asked an insightful question in class, contributed to a class discussion, and interacted with faculty during lecture class sessions. Frequency was measured on a scale from $1=$ never to $6=$ very often, and the factor developed from these items had good reliability $(\alpha=.84)$.

Items used to measure students' academic skills development included students' perception of their current (that is, end of the spring semester) analytical and critical thinking skills, ability to read and comprehend academic material, ability to be clear and effective when writing, and understanding of a specific field of study. Students rated their skills on a scale from $1=$ very poor to $6=$ excellent, and the factor developed from these items had good reliability $(\alpha=.88)$.

Students' engagement in scholarship was measured through eight items in which students were asked to rate the frequency with which they had explained methods, ideas, or concepts and used them to solve problems; broke down material into component parts or arguments into assumptions to see the basis for different outcomes and conclusions; judged the value of information, ideas, actions, and conclusions based on the soundness of sources, methods, and reasoning; created or generated new ideas, products, or ways of understanding; used facts and examples to support their viewpoint; incorporated ideas or concepts from different courses when completing assignments; examined how others gathered and interpreted data and assessed the soundness of their conclusions; and reconsidered their own position on a topic after assessing the arguments of others. Frequency was measured on a scale from $1=$ never to $6=$ very often, and the factor developed from these items had good reliability $(\alpha=.92)$.

\section{Analysis}

We conducted all analyses using SPSS 21.0. We used a factor analysis for the purpose of data reduction - to explain a larger set of measured variables with a smaller set of latent constructs. To develop the dependent and independent measures used in this study, we developed a factor analysis on 36 survey items with oblique rotation (promax) using Velicer's minimum average partial (MAP) method. ${ }^{20}$ We used the procedures outlined by Courtney ${ }^{21}$ to analyze the data using SPSS R-Menu v2.0. ${ }^{22}$ Velicer's MAP values suggested a distinct eighth step minimum squared average partial correlation suggesting eight factors: academic engagement, sense of belonging, campus climate, academic skills, library skills, academic disengagement, engagement in scholarship, and classmate interactions. We computed the factor scores using the regression method and saved them as standardized scores with a mean of zero and a standard deviation of one.

After this step was taken to reduce the data, we used hierarchical regression analyses to measure the relationships between the independent variables, which included students' precollege characteristics, collegiate experiences, use of academic libraries, and the dependent variables, which included students' academic engagement, academic skills, engagement in scholarship, and fall semester GPA. Hierarchical multiple 


\begin{tabular}{|l|c|c|}
\hline \multicolumn{2}{|c|}{ TABLE 1 } \\
\multicolumn{2}{|c|}{ Means, Standard Deviations, and Coding for Variables } \\
\hline Categorical Variables Used in Analysis & n & \% \\
\hline Female & 650 & 60.86 \\
\hline International & 58 & 5.43 \\
\hline Multiracial & 37 & 3.46 \\
\hline Hispanic & 9 & 0.84 \\
\hline Asian & 99 & 9.27 \\
\hline Black & 19 & 1.78 \\
\hline First-generation & 276 & 25.84 \\
\hline Pell grant & 249 & 23.31 \\
\hline Business college & 83 & 7.77 \\
\hline Engineering and biology colleges & 365 & 34.18 \\
\hline Education college & 85 & 7.96 \\
\hline Design college & 50 & 4.68 \\
\hline Agriculture college & 61 & 5.71 \\
\hline Freshman seminar & 334 & 31.27 \\
\hline Residence hall & 926 & 86.70 \\
\hline Access to Success program & 66 & 6.18 \\
\hline Books & 490 & 45.88 \\
\hline Web-based services & 488 & 45.69 \\
\hline Reference services & 287 & 26.87 \\
\hline Classes & 184 & 17.23 \\
\hline Continuous Variables Used in Analysis & 1.29 & $\mathbf{s d}$ \\
\hline Workstation & 28.34 & 3.76 \\
\hline ACT & 10.54 & 12.77 \\
\hline AP credits & 7.71 & 2.03 \\
\hline Reading completed & 4.42 & 1.54 \\
\hline Time studying & 954 \\
\hline
\end{tabular}

regression analyses are commonly used by researchers seeking to examine the variance specific measures explain above and beyond the variance accounted for by control measures. ${ }^{23}$ Given that we were interested in the different effects of using academic libraries above and beyond other indicators, this methodology was appropriate for the present analysis. After running the regressions, we examined assumptions of multicollinearity, homoscedasticity, linearity, and independent/normal errors. The results suggested the assumptions were not violated.

\section{Limitations}

There are a few limitations to this study that are important to acknowledge. First, while the sample is relatively representative of the population of first-year students at the institution, there is a slight bias in the sample of female students and white students, who are overrepresented. Second, it is likely that students who are engaged 
at the institution may have responded to the survey, while those who are significantly less engaged may not have completed the survey (especially if they were considering withdrawing from the institution). Furthermore, the sample was drawn from a large, public research university, which may limit the potential generalizability of the results to other institutions. Finally, in this research study we only analyzed students' use of library materials and did not assess the innumerable ways in which academic libraries influence students' experiences as partners in the educational enterprise.

\section{Results}

\section{Academic Engagement}

The first model regressing students' academic engagement on their precollege demographics, collegiate experiences, and academic library use explained 35.7 percent of the variance in students' academic engagement (table 2). In the first block of variables entered, the results suggested that female students reported lower academic engagement, on average, than males $(\beta=-.095, p<.01)$. Asian students and first-generation college students also had lower academic engagement, on average, compared to their peers $(\beta=-.058, p<.05$ and $\beta=-.062, p<.05$, respectively). The demographic variables contributed a significant amount of variance to students' academic engagement $\left(R^{2}=\right.$ $.049, p<.001)$.

In the second block of the analyses, the results suggested students in the engineering and biology colleges had lower academic engagement, on average, compared to their peers $(\beta=-.171, p<.01)$, although students in the education college had higher academic engagement, on average, compared to their peers $(\beta=.139, p<.01)$. Students who lived in the residence halls had lower academic engagement than students who lived off campus $(\beta=-.063, p<.05)$. The percentage of required reading completed by students, time spent studying, frequency of classmate interactions, library skills, and sense of belonging were positively associated with students' academic engagement, although their perceptions of campus climate were negatively associated with their academic engagement. In this block, the variables explained a significant amount of variance in students' academic engagement above that explained by the first block $\left(R^{2} \Delta=.179, p<.001\right)$.

Finally, the results from the third block of variables also suggested that students' use of academic libraries explained a significant amount of variance in their academic engagement above and beyond that explained by the precollege and collegiate experience variables $\left(R^{2} \Delta=.130, p<.001\right)$. Three areas of academic library use were positively and significantly associated with students' academic engagement: students who had used books (interlibrary loans, e-books, or traditional book loans), students who used web-based services (academic journals, databases, or the libraries' website), and students who used reference services (reference librarian or peer reference consultant) had significantly higher academic engagement over their peers who did not use these services $(\beta=.124, p<.001 ; \beta=.256, p<.001$; and $\beta=.062, p<$ .01 , respectively).

\section{Academic Skills Development}

The second model regressing students' academic skills development on their precollege demographics, collegiate experiences, and academic library use explained 58.6 percent of the variance in students' academic skills development. The results from the first block of variables suggested that female students reported lower academic skills than males $(\beta=-.102, p<.001)$. Asian students also reported lower academic skills, on average, compared to their peers $(\beta=-.087, p<.001)$. Students' ACT scores were positively associated with their academic skills $(\beta=.070, p<.05)$. All of the variables measur- 


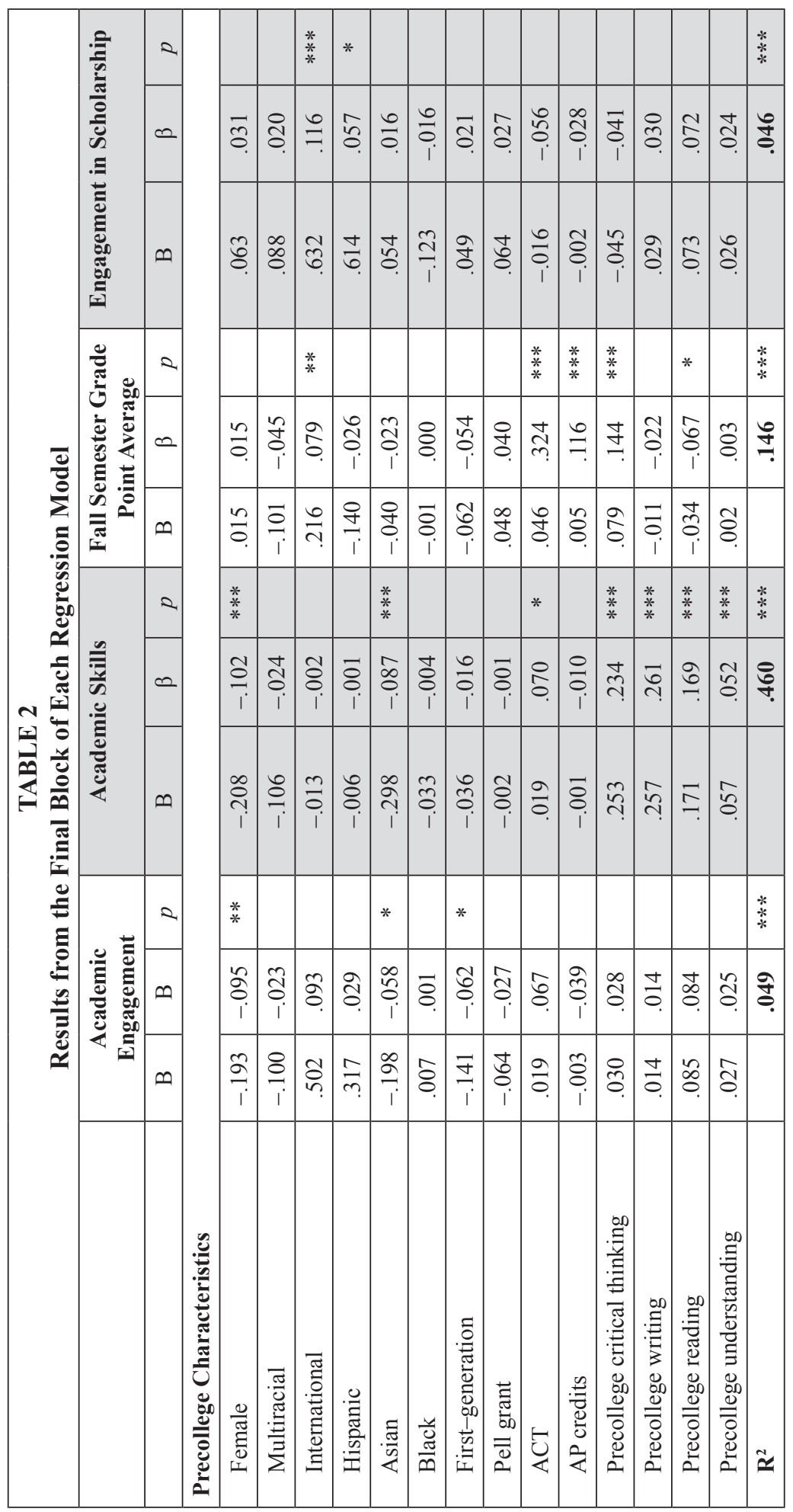


Beyond Books 17

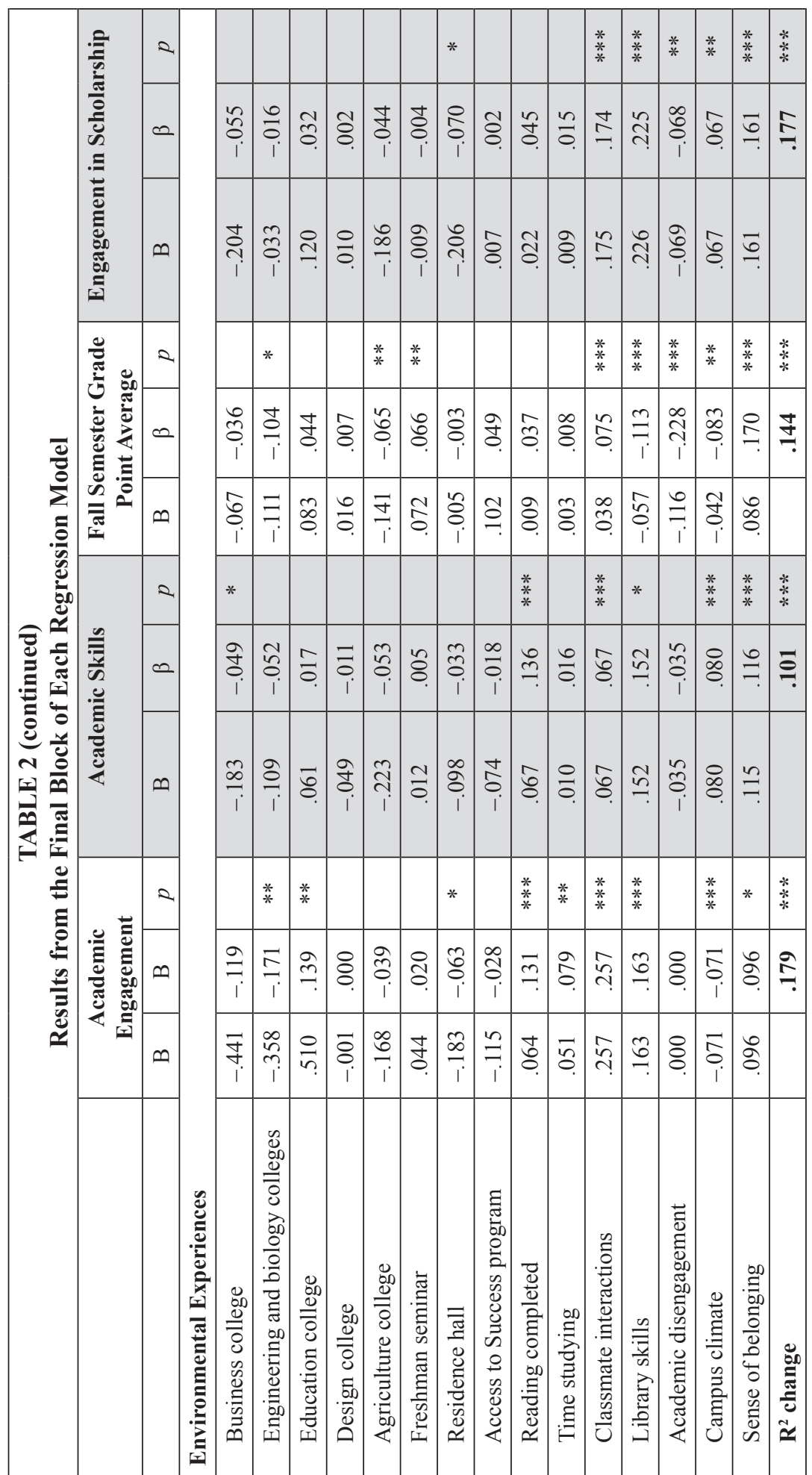




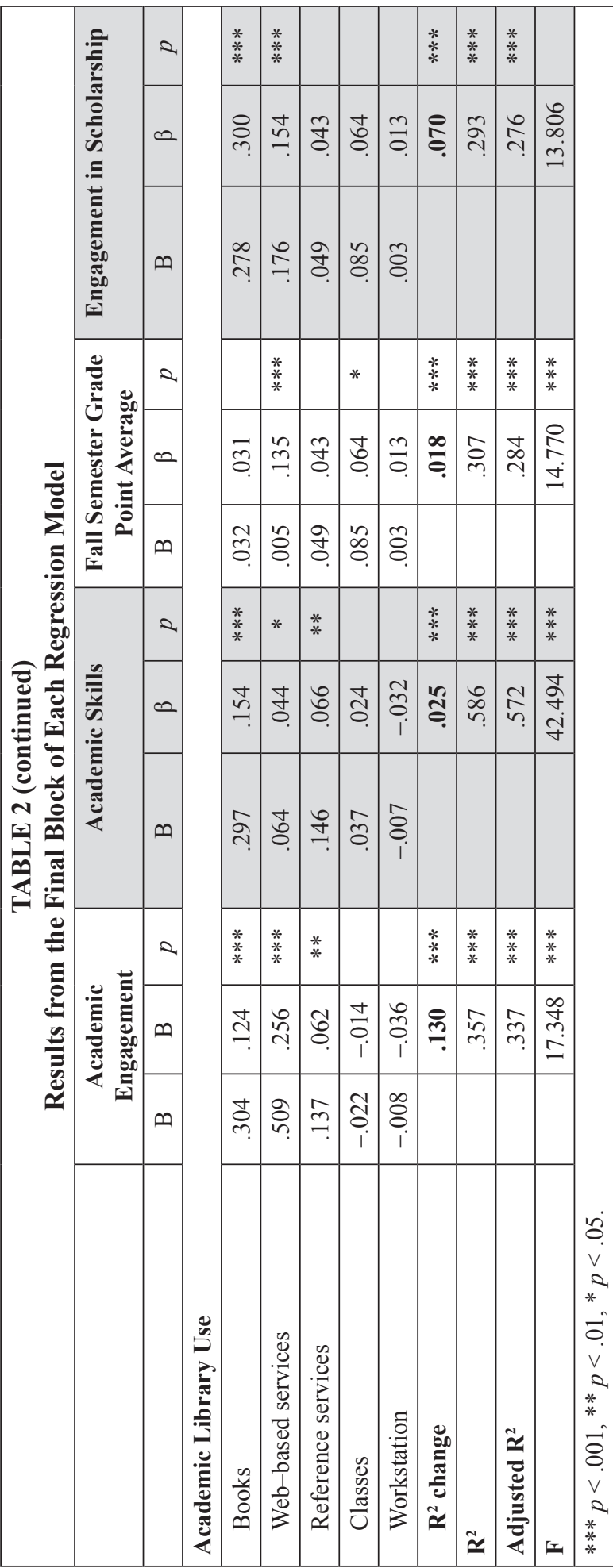

ing students' self-reported academic skills when they started college were positively associated with their current rating of academic skills. The demographic and precollege variables contributed a significant amount of variance in students' academic skills $\left(R^{2}=\right.$ $.460, p<.001)$.

In the second block of the analyses, the results suggested that students in the business college reported lower academic skills development, on average, compared to their peers $(\beta=$ $-.049, p<.05)$. The percentage of required reading completed by students, frequency of classmate interactions, library skills, perception of campus climate, and sense of belonging were positively associated with their academic skills development. This block explained a significant amount of variance in students' academic skills above that explained by the first block $\left(R^{2} \Delta=.101\right.$, $p<.001$ ).

Finally, the results from the third block of variables entered also suggested that students' use of academic libraries explained a significant amount of variance in their academic skills above and beyond that explained by the precollege and collegiate experience variables $\left(R^{2} \Delta\right.$ $=.025, p<.001)$. Three areas of academic library use were positively and significantly associated with students' academic skills: students who had 
used books (interlibrary loans, e-books, or traditional book loans), students who used web-based services (academic journals, databases, or the libraries' website), and students who used reference services had significantly higher academic skills over their peers who did not use these services $(\beta=.154, p<.001 ; \beta=.044, p<.05$; $\beta=.066, p<.01$, respectively).

\section{Grade Point Average}

The third model regressing students' fall semester grade point average on their precollege demographics, collegiate experiences, and academic library use explained 30.7 percent of the variance in students' GPA. In the first block of variables, the results suggested that international students reported a higher GPA, on average, compared to their peers $(\beta=.079, p<.01)$. Students' ACT scores and number of AP credit classes were also positively associated with their fall semester GPA $(\beta=.324, p<.001$ and $\beta=$ $.116, p<.001$, respectively). Students' precollege rating of analytical and critical thinking was positively associated with their GPA $(\beta=.144, p<.001)$, although their perception of precollege reading skills was negatively associated with their GPA $(\beta=-.067, p<$ .05). These demographic and precollege variables contributed a significant amount of variance in students' GPA $\left(R^{2}=.146, p<.001\right)$.

In the second block of the analyses, the results suggested that students in the engineering and biology colleges and agriculture college reported a lower GPA, on average, compared to their peers $(\beta=-.104, p<.05$ and $\beta=-.065, p<.01$, respectively). Students who participated in a freshman seminar reported a higher GPA, on average, compared to their peers $(\beta=.066, p<.001)$. Students' library skills, academic disengagement, and perception of campus climate were negatively associated with their GPA, although students' sense of belonging and classmate interactions were positively associated with their GPA. This block explained a significant amount of variance in students' GPA above that explained by the first block $\left(R^{2} \Delta=.144, p<.001\right)$.

Finally, in the third block of analyses, the results also suggested that students' use of academic libraries explained a significant amount of variance in their GPA above and beyond that explained by the precollege and collegiate experience variables $\left(R^{2} \Delta\right.$ $=.018, p<.001$ ). Two areas of academic library use were positively and significantly associated with students' academic engagement: students who used web-based services (academic journals, databases, or the libraries' website) and students who engaged in libraries instruction (workshops, classes, or course-integrated instruction) had significantly higher GPA, on average, over their peers who did not use these services $(\beta=$ $.135, p<.001$ and $\beta=.064, p<.05$, respectively).

\section{Engagement in Scholarship}

The fourth model regressing students' engagement in scholarship on their precollege demographics, collegiate experiences, and academic library use explained 29.3 percent of the variance in students' engagement in scholarship. The results from the first block of variables entered suggested that international and Hispanic students reported higher engagement in scholarship, on average, compared to their peers $(\beta=.116, p<.01$ and $\beta=.057, p<.05)$. These demographic and precollege variables contributed a significant amount of variance in students' development of scholarship $\left(R^{2}=.046, p<.001\right)$.

In the second block of the analyses, the results suggested that students who lived in the residence halls reported lower engagement in scholarship compared to their peers $(\beta=-.070, p<.05)$. Students' frequency of classmate interactions, library skills, perceptions of campus climate, and sense of belonging were positively associated with their engagement in scholarship, while their academic disengagement was negatively associated with their engagement in scholarship. This block explained a significant 
amount of variance in students' academic skills development above that explained by the first block $\left(R^{2} \Delta=.177, p<.001\right)$.

Finally, the results from the third block of the analyses also suggested that students' use of academic libraries explained a significant amount of variance in their engagement in scholarship above and beyond that explained by the precollege and collegiate experience variables $\left(R^{2} \Delta=.070, p<.001\right)$. Two areas of academic library use were positively and significantly associated with students' academic engagement: students who had used books (interlibrary loans, e-books, or traditional book loans) and students who used web-based services (academic journals, databases, or the libraries' website) had significantly higher academic skills, on average, over their peers who did not use these services $(\beta=.300, p<.001$ and $\beta=.154, p<.001$, respectively).

\section{Discussion and Recommendations}

The results of the study suggest students' use of academic libraries explains a significant amount of variance in students' academic engagement, academic skills development, engagement in scholarship, and grade point average above and beyond the variance explained by precollege variables, demographic characteristics, and collegiate experiences. Students who borrowed books (including traditional books, e-books, and interlibrary loans) were more likely than their peers who did not borrow books to be engaged in their academic work, to develop academic skills like critical thinking and reading/writing, and to engage in scholarly activities, including analyzing materials, using facts and examples to support claims, and incorporate ideas and topics across disciplines. First-year students who used webbased library services (like electronic journals, databases, and the library website) were more likely than their peers to be engaged in academic activities, develop academic skills, focus on scholarly work, and have higher grade point averages. Students who participated in library classes or workshops were more likely than their peers to earn a higher grade point average by the end of their fall semester. Finally, students who used reference services were more likely to be academically engaged. We found no significant effects for students' use of library workstations on their academic outcomes.

The explanatory power of academic library use was low in these results, overall: these models explained approximately one-third to three-fifths of the variances in the outcome variables, with library use contributing between 1.8 percent and 13.0 percent of the final variances in the dependent variables. Subsequently, the examinations of the standardized coefficients suggest that the relationships observed are small in magnitude. While these relationships are small, they are still significant in predicting first-year students' academic outcomes above and beyond the precollege and collegiate variables entered into the models.

This study also highlights the importance of considering the relationships between students' precollege demographics, precollege skills, and collegiate experiences in predicting students' academic outcomes. For instance, researchers attempting to assess the impact of academic libraries on students' academic skills development are encouraged to consider the influence of students' academic skills when they started on campus. As discovered in the results of this paper, students' demographic characteristics often play a part in predicting their academic outcomes, although these demographic variables were not as meaningful to students' academic outcomes as their college experiences.

We also found that students' college of enrollment mattered in terms of predicting their academic outcomes, as did the campus climate and the frequency with which students interacted with classmates on academic work (or even completed their required reading each week). The results of this study confirm that the amount of time 
and energy students invest in their higher education and the extent to which students feel welcomed and supported by the institution will yield greater benefits for students. ${ }^{24}$ Therefore, assessment research undertaken by academic libraries should continue to control for these effects on students' outcomes. Overall, given that this study controlled for such effects, the results support the burgeoning body of literature investigating the potential benefits of students' use of academic libraries on their overall academic success, engagement, and development. ${ }^{25}$

\section{Conclusion}

The results of this study suggest that students' use of academic libraries is positively associated with a variety of academic outcomes above and beyond other key measures, including demographic characteristics and collegiate environmental experiences. This study provides additional support for the ongoing importance of students' use of academic libraries and the critical roles that libraries play in students' academic development, engagement, skills, and achievement.

\section{Notes}

1. Krista M. Soria, Jan Fransen, and Shane Nackerud, "Library Use and Undergraduate Student Outcomes: New Evidence for Students' Retention and Academic Success," portal: Libraries and the Academy 13, no. 2 (2013): 147-64.

2. Krista M. Soria, Jan Fransen, and Shane Nackerud, "Stacks, Serials, Search Engines, and Students' Success: First-Year Undergraduate Students' Library Use, Academic Achievement, and Retention," Journal of Academic Librarianship 40, no. 1 (2014): 84-91.

3. Shun Han Rebekah Wong and T.D. Webb, "Uncovering Meaningful Correlation between Student Academic Performance and Library Material Usage," College E Research Libraries 72, no. 4 (2011): 361-70.

4. Ethelene Whitmire, "Development of Critical Thinking Skills: An Analysis of Academic Library Experiences and Other Measures," College E Research Libraries 59, no. 3 (1998): 266-73.

5. Jennifer Wells, "The Influence of Library Usage on Undergraduate Academic Success," Australian Academic E Research Libraries 26, no. 2 (1995): 121-28.

6. Megan Oakleaf, "Correlating Library Services, Expertise, and Resources with Student Learning," Information Outlook 18, no. 2 (2014): 13-16.

7. Hamish Coates, Engaging Students for Success: Australasian Student Engagement Report, Australian Survey of Student Engagement (Victoria, Australia: Australian Council for Educational Research, 2009).

8. Karin de Jager, "Impacts and Outcomes: Searching for the Most Elusive Indicators of Academic Library Performance," paper read at the 4th Northumbria International Conference on Performance Measurement in Libraries and Information Services, 2001.

9. George D. Kuh and Robert M. Gonyea, "The Role of the Academic Library in Promoting Student Engagement in Learning," College E Research Libraries 64, no. 4 (2003): 256.

10. Graham Stone and Bryony Ramsden, "Library Impact Data Project: Looking for the Link between Library Usage and Student Attainment," College E Research Libraries 74, no. 6 (2013): 546-59.

11. Alexander Astin, What Matters in College: Four Critical Years Revisited (San Francisco, Calif.: Jossey-Bass, 1993).

12. Ernest T. Pascarella, Gregory C. Wolniak, and Christopher T. Pierson, "Explaining Student Growth in College When You Don't Think You Are," Journal of College Student Development 44, no. 1 (2003): 122-26.

13. Krista M. Soria, Beth Lingren Clark, and Laura Coffin Koch, "Investigating the Academic and Social Benefits of Extended New Student Orientations for First-year Students," Journal of College Orientation and Transition 20, no. 2 (2013): 33-45.

14. Krista M. Soria and Michael J. Stebleton, "Social Capital, Academic Engagement, and Sense of Belonging among Working-class College Students," College Student Affairs Journal 31, no. 2 (2013): 139-53.

15. Ex Libris Group, Aleph integrated library system [computer software], 2012, Chicago, Ill.

16. OCLC $^{\circledR}$, ILLiad (version 8.4) [computer software], 2013, Dublin, Ohio.

17. OCLC ${ }^{\circledR}$, QuestionPoint ${ }^{\mathrm{TM}}$ [computer software], 2012, Dublin, Ohio. 
18. Crybrarian Corporation $®$, Cybrarian [computer software], 2013, available online at www. cybrarian.com/ [accessed 1 December 2016].

19. Drupal, Drupal [open source computer software], 2013, available online at https://drupal. org/ [accessed 1 December 2016].

20. Wayne F. Velicer, "Determining the Number of Components from the Matrix of Partial Correlations," Psychometrika 41, no. 3 (1976): 321-27.

21. Matthew Gordon Ray Courtney, "Determining the Number of Factors to Retain in EFA: Using the SPSS R-menu v2.0 to Make More Judicious Estimates," Practical Assessment, Research, E Evaluation 18, no. 8 (2013): 1-14.

22. Mario Basto and Jose Manuel Pereira, "An SPSS R-Menu for Ordinal Factor Analysis," Journal of Statistical Software 46, no. 4 (2012): 1-29.

23. John V. Petrocelli, "Hierarchical Multiple Regression in Counseling Research: Common Problems and Possible Remedies," Measurement and Evaluation in Counseling and Development 36 (2003): 9-22.

24. Astin, What Matters in College.

25. Soria, Fransen, and Nackerud, "Library Use and Undergraduate Student Outcomes"; Soria, Fransen, and Nackerud, "Stacks, Serials, Search Engines, and Students' Success." 